\title{
USO DE PLASMA RICO EM PLAQUETAS NA ODONTOLOGIA: REVISÃO INTEGRATIVA
}

\author{
USE OF PLATELET-RICH PLASMA IN DENTISTRY: INTEGRATIVE REVIEW
}

\author{
Gabriela Cunha Corbacho Porto' \\ Mirelle Sena Reis ${ }^{1}$ \\ Tais Hana Kataoka ${ }^{1}$ \\ Kaliane Rocha Soledade ${ }^{2}$
}

\begin{abstract}
O periodonto tem como objetivo inserir, sustentar e proteger o dente, sendo dividido em periodonto de proteção (gengiva) e periodonto de sustentação (osso alveolar, ligamento periodontal e cemento). Em desequilíbrio com o hospedeiro, surgem as doenças que o afetam como a gengivite: uma inflamação no periodonto de proteção que tem como principal tratamento a remoção da causa. Já a periodontite é caracterizada pela perda de inserção do dente e pela destruição dos tecidos periodontais causada por microrganismos que, mesmo após tratamento, deixam sequelas. Afim de reverter estas sequelas, a regeneração periodontal compreende uma sequência de eventos a nível molecular e celular que visa à formação de osso alveolar, cemento e ligamento periodontal, para devolver a função que foi perdida. Através da utilização do plasma rico em plaquetas (PRP) obtido através da coleta e centrifugação do sangue do próprio paciente, objetiva-se a rápida cicatrização de feridas e reparação de sequelas, como as deixadas pela periodontite, além de ser rico em concentrados sanguíneos e células capazes de reparar tecido ósseo, o que contribui na regeneração periodontal, como evidenciados nos resultados de pesquisas clínicas mais atuais.
\end{abstract}

PALAVRAS-CHAVES: Periodonto. Plasma Rico em Plaquetas. Regeneração Tecidual Guiada Periodontal.

The purpose of the periodontium is to insert, support and protect the tooth, being divided into periodontium of protection (gingiva) and support periodontium (alveolar bone, periodontal ligament and cement). Any unbalance in the host might cause diseases such as gingivitis, an inflammation of the periodontium of protection which might be healed by removing its cause. On the other hand, periodontitis is characterized by the loss of tooth insertion and the destruction of the periodontal tissues caused by microorganisms, but even after treatement it leaves sequelae. In order to revert these sequelae, periodontal regeneration, which is a sequence of events at molecular and cellular levels that aim at the formation of alveolar bone, cementum and periodontal ligament, can be used to restore the functions that were lost. Platelet-rich plasma (PRP) obtained through the collection and centrifugation of the patient's own blood, can be used to repair and rapidly heal the wounds as in the case of periodontal disease. PRP besides being rich in blood concentrates and cells capable of repairing bone, has been used since the 1990s and plays an important role in periodontal regeneration. The objective of this work was to demonstrate what platelet-rich plasma is, how it is obtained, and how it is used for periodontal regeneration.

Keywords: Periodontium. Platelet Rich Plasma. Periodontal Guided Tissue Regeneration

\footnotetext{
${ }^{1}$ Graduando em Bacharelado em Odontologia na Faculdade Maria Milza, Governador Mangabeira-BA; gabrielaporto23@outlook.com; tais.hana@hotmail.com; senamili@hotmail.com. CV: http://lattes.cnpq.br/9607853441533749. CV: http://lattes.cnpq.br/3777446628771049

${ }^{2}$ Mestrado e Doutorado em Processos Interativos dos Órgãos e Sistemas da Universidade Federal da Bahia. Coordenadora do Curso de Odontologia da Faculdade Maria Milza, Governador Mangabeira-BA.; krsoledade@gmail.com; http://lattes.cnpq.br/1714433341112690
} 


\section{INTRODUÇÃO}

O periodonto, estrutura com a principal função de inserir e sustentar o dente no alvéolo, é dividido em periodonto de proteção, que compreende o tecido gengival, e o periodonto de sustentação, que inclui o tecido ósseo alveolar, cemento e ligamento periodontal (CARRANZA, 1983; LINDHE et al., 2010). Na presença de um desequilíbrio entre o hospedeiro e o desafio microbiano, a partir do acúmulo de biofilme, originam-se as doenças que atingem estes tecidos por alterações significativas em seu metabolismo. Quando estas alterações compreendem apenas os tecidos de revestimento, desenvolve-se gengivite, que, se não tratada, pode evoluir para lesões irreversíveis nos tecidos de sustentação, determinando assim quadros de periodontite (DOMINGUES et al., 2010).

Segundo Requicha, Gomes e Viegas (2015), nas doenças periodontais observa-se a perda de inserção, inflamação e reabsorção óssea, e sua reposição é alvo de preocupação para os periodontistas. Sendo assim, com o avanço tecnológico a reconstrução do tecido ósseo perdido tem sido foco de pesquisas ao longo dos anos, destacando-se, desde os anos 50 , as terapias de regeneração periodontal (CORRÊA, 2006).

A regeneração periodontal é vista como um conjunto de eventos a nível molecular e celular que tem como objetivo formar novo osso alveolar, cemento e ligamento periodontal, restaurando a função de cada um destes componentes. Esta neo-formação depende de diversos fatores, mas pode ser atingida por uma grande variedade de métodos. Dentre estes, a utilização do plasma rico em plaquetas vem ganhando destaque, com seus resultados analisados em pesquisas científicas mais atuais (MARINHO, 2011).

O plasma rico em plaquetas (PRP) é considerado um produto autógeno, orgânico, atóxico e não imunorreativo que vem sendo usado desde a década de 90 nas áreas de cirurgia, para reconstrução de tecidos bucais e na implantodontia. Caracteriza-se por acelerar a formação óssea, devido à ação de fatores de crescimento específicos que vão iniciar quase todos os processos cicatrizantes (CAMARGO et al., 2012).

Diante do exposto, o objetivo do trabalho é realizar uma revisão integrativa da literatura atual a respeito da obtenção do plasma rico em plaquetas e de sua eficácia nas diversas áreas da Odontologia.

\section{MATERIAIS E MÉTODOS}

O trabalho foi elaborado como uma revisão integrativa do tema citado. Esse tipo de revisão é descrita por Whittemore (2005) como uma forma ampla de ser abordado um assunto, já que poderão ser utilizados estudos experimentais e não experimentais para atingir os objetivos propostos. Mendes (2008) ratifica que esse tipo de estudo irá organizar todos os resultados encontrados na literatura, proporcionando para o leitor um maior aprofundamento do tema.

Com base nos estudos de Melo (2011), para a realização de uma revisão integrativa da literatura é necessário formular a pergunta que será estudada no corpo do artigo. Esta pergunta será respondida através de artigos selecionados em plataformas digitais de cunho confiável, utilizando critérios de inclusão e exclusão para a seleção dos artigos. Por fim, será realizada a análise das informações para a obtenção dos resultados e sua discussão.

A revisão integrativa foi baseada na seguinte questão: quais são os achados na literatura sobre o plasma rico em plaquetas, qual a sua forma de obtenção e seus benefícios na Odontologia? Em seguida foi realizada uma busca nas bases digitais Scielo, PubMed e Medline utilizando os descritores na língua portuguesa e sua variação na língua inglesa: periodonto, plasma rico em plaquetas e regeneração tecidual guiada periodontal.

Os critérios de inclusão para a seleção dos dados foram artigos, monografias, teses ou capítulos de livros que contemplassem o tema e estivessem na íntegra, publicados em inglês, espanhol ou português e fossem indexados nos referidos bancos de dados acima. Após a seleção dos artigos, foi realizada a análise das informações para discussão. 
Após a busca de artigos, foram selecionados 50 artigos para leitura. Após avaliação minuciosa com base nos critérios de inclusão, foram escolhidos 21 artigos, 5 monografias, 1 tese e 3 livros. As informações obtidas foram organizados em quatro categoriais: regeneração periodontal; plasma rico em plaquetas (PRP): composição e função, obtenção do PRP; e resultados obtidos nas diversas áreas da odontologia com uso do PRP, como apresentamos a seguir:

\section{REGENERAÇÃO PERIODONTAL}

Segundo Pereira (2011), a regeneração periodontal é descrita como a cicatrização após o tratamento periodontal, que visa à redução das sequelas deixadas e restauração dos tecidos periodontais, devolvendo a sua anatomia e função normal. Esta modalidade de tratamento tem se mostrado promissora e um desafio na prática clínica cotidiana.

Para Nanci (2008), os progressos na compreensão da biologia celular e molecular dos tecidos periodontais, é possível recuperar os possíveis processos biológicos ligados à reparação e à regeneração dos tecidos acometidos pela periodontite. De acordo com o autor, enquanto ocorre o desenvolvimento da lesão periodontal, há um grande número de mudanças bioquímicas quantitativas e qualitativas acontecendo nos componentes da matriz extracelular dos tecidos que compõem o periodonto e que resultam em mais destruição.

Durante os últimos anos, a periodontia clínica tem se dedicado a regenerar os tecidos periodontais, em estrutura e função. Neste sentido, foi observado que os efeitos produzidos pela gengivite podem ser reparados, desde que haja a remoção do fator causal. Já nos casos de periodontite, s foi acometido osso alveolar, não há como reverter este processo (NANCl, 2008). Essa regeneração é difícila, porque há reparação simultânea de quatro tecidos diferentes. E os eventos celulares e moleculares envolvidos no processo são complexos e necessitam de uma correta e completa integração para que sejam seguidos por uma sucessão de eventos, sendo eles a indução da estimulação de uma resposta inflamatória inicial, recrutamento de células diferentes e especificas, indução da proliferação, diferenciação e esforços combinados de diferentes tipos de células (NANCl, 2008).

A regeneração periodontal tem como objetivo originar um novo ligamento periodontal capaz de se inserir em um novo cemento acelular e osso neoformado. Para isso, foram desenvolvidas três técnicas: a Regeneração Tecidual Guiada (RTG), Fatores de Crescimento Polipeptídicos (FCP) e as Proteínas da Matriz do Esmalte (PME).

A regeneração tecidual guiada consiste no desenvolvimento de uma barreira física que é introduzida no momento da cirurgia periodontal e separa o tecido conjuntivo do retalho da superfície radicular curetada. Esta membrana tem a finalidade de prevenir a migração de células gengivais em sentido apical sobre a superfície radicular, que excluiria os tecidos conjuntivos gengivais de lugares indesejados (local da cicatrização) e simplificaria a repopulação de células do ligamento periodontal na ferida (NANCl, 2008).

Já para Pereira, Pinho e Almeida (2012), a RTG consiste em isolar com uma membrana a parte que foi contaminada, para que as células do ligamento periodontal tenham a capacidade de proliferar e formar novas fibras de sharpey, osso e cemento. Durante o processo de cicatrização é formada uma extensa camada de tecido epitelial que impede esta proliferação. Por isso a ideia de isolamento, para se obter espaço para esse processo.

A colocação das membranas de RTG sobre o defeito periodontal, combinada ou não com o uso de materiais de preenchimento ósseo referidos anteriormente, permite que, durante o processo de regeneração, se possam recuperar as fibras do ligamento periodontal e o tecido ósseo sem que esse processo seja prejudicado pela proliferação de células epiteliais provenientes da gengiva (REQUICHA; GOMES; VIEGAS, 2015).

Segundo os autores supracitados, esta técnica de isolar os espaços é chamada de técnica da seletividade celular, que é uma forma de selecionar quais células vão agir naquele determinado local que, como no caso da RGT, são as células do ligamento periodontal.

Um grupo promissor de fatores de crescimento polipeptídicos é o das proteínas morfogenéticas ósseas, que apresentam bom potencial para estimular a regeneração do osso e do cemento. Preparados 
isolados de fatores de crescimento, misturas de fatores de crescimento, como aquelas encontradas em preparos de plasma rico em plaquetas, também tem sido considerada importantes auxiliares na promoção da regeneração periodontal (NANCl, 2008).

Para Pereira (2011), a PME tem tentado, assim como a RGT, trazer essa regeneração periodontal para o periodonto. Nesse contexto, foram observadas as amelogeninas, células extraídas de germes dentários suínos durante a fase da odontogênese, que tem participação na formação de ligamento periodontal, osso e cemento, aplicados diretamente no periodonto danificado pela doença periodontal.

Segundo Nanci (2008), a PME busca reproduzir em adultos o período da embriogênese. Sendo assim, é feita a aplicação de extratos da matriz do esmalte no momento da cirurgia periodontal para que haja a indução da regeneração periodontal e a reprodução de eventos moleculares da cementogênese. Porém não está claro ainda se essas proteínas vão agir como mensageiros indutores para que as células passem pelo processo de regeneração ou se vão agir alterando o tecido.

A matriz extracelular do cemento apresenta o potencial de regular a diferenciação de células percursoras em cementoblastos e a subsequente formação de matriz de cemento e inserção de fibras. Portanto, componentes do cemento podem ser capazes de fornecer sinais informativos para o recrutamento, a proliferação e a diferenciação de células periodontais e podem regular a regeneração do cemento e de componentes periodontais adjacentes (NANCl, 2008).

Com isso, muitos avanços significativos vêm sendo feitos em relação ao entendimento de como a regeneração periodontal pode ser feita, mas ainda não há uma forma de prever os resultados e guia-los de maneira a se comportarem como esperado (NANCl, 2008). Para tanto, a regeneração periodontal parece uma coisa distante da realidade da prática clínica cotidiana.

A reparação dos tecidos dentários de suporte depende do grau de dano. Se o dano for mínimo e as células foliculares programadas estiverem disponíveis, haverá reparação envolvendo a formação de tecido cicatricial, mas a cicatriz é rapidamente remodelada para restaurar a arquitetura normal. Se o dano for mais extenso, o resultado depende da repopulação de células no defeito. Em suma, os tecidos orais utilizam um mecanismo básico para a reparação, mas fatores locais beneficiam e prejudicam esse processo (NANCl, 2008)

\section{PLASMARICO EM PLAQUETAS (PRP): COMPOSIÇÃO E FUNÇÃO}

O gel de plaquetas, componente do plasma rico em plaquetas vem sendo utilizado desde a década de 90 em diversas áreas da Odontologia com a finalidade de acelerar e melhorar a cicatrização em tecidos lesionados. Hoje, sabemos que o PRP dentre suas vantagens vai permitir crescimento e maturação óssea, com papel nos mecanismos de reparação do tecido duro e mole, promovendo então a cicatrização de tecidos, regeneração e proliferação de células, segundo Camargo et al (2012).

É composto por plaquetas, cerca de 95\% do seu volume, segundo Dinato et al. (2001), leucócitos e plasmas, em geral células brancas em torno de $1 \%$ e $4 \%$ de células vermelhas. De acordo com Camargo et al (2012), esses componentes serão retirados do próprio paciente antes da cirurgia, por isso considerado autógeno, eliminando a possibilidade de transmissão de doenças e reações imunogênicas.

Seu potencial regenerativo só foi descoberto em 1974, segundo Azevedo (2014). A partir de uma pesquisa por Ross e colaboradores com a separação do sangue descobriram os fatores de crescimento derivado das plaquetas com a capacidade promover o crescimento vascular e proliferação de fibroblastos proporcionando assim um aumento na síntese de colágeno.

Os fatores de crescimento presente no concentrado de plaquetas (PRP) são derivados pela degradação plaquetária e reconhecidos cientificamente por diversas vantagens na sua utilização, são mediadores biológicos naturais que vão ter influência no processo de reparo e regeneração óssea, segundo Scarso et al (2001). Sendo assim, os fatores mais conhecidos são os: PDGF, fator de crescimento derivado das plaquetas; o TGFb; o fator de crescimento semelhante à insulina (IGF) e o fator de crescimento epidérmico (EGF) que este pode ser encontrado em vários tecidos em fase de cicatrização (COSTA, SANTOS, 2016).

De acordo com Scarso et al (2001), o primeiro fator a ser descoberto foi o derivado das plaquetas (PDGF), além de ser considerado um dos principais por ser encontrado primeiramente em locais de 
lesão, como a função de guia da revascularização, síntese de colágeno e regeneração óssea, e por ter duplo papel, segundo Costa (2016), de fator de crescimento e hemostasia. O seu uso em defeitos periodontais deve-se ao fato de aumentar o reparo e a regeneração periodontal. $O$ fator de crescimento $\beta$ (TGF $\beta$ ) é encontrado no PRP nas formas de $\beta 1$ e $\beta 2$, tem como objetivo a cicatrização do tecido conjuntivo e regeneração óssea.

Já o fator de crescimento insulínico (IGF) vai conseguir estimular a síntese do colágeno e a proliferação dos fibroblastos. Por fim, o fator de crescimento da epiderme - EGF, segundo Costa (2016), tem como função estimular a proliferação das células mesenquimais, epiteliais e formação do tecido de granulação, além de potencializar outros fatores de crescimento.

Vê-se, portanto que esses fatores de crescimento através da degradação das plaquetas vão fazer com que o plasma rico em plaquetas tenha a função de mitogênese, angiogênese e quimiotaxia, segundo Scaranto (2002). Em locais com o tecido lesionado ou defeitos ósseos, ao utilizar o plasma rico em plaquetas, a sua degradação vai liberar os fatores de crescimento e estes, por sua vez, vão regular o processo de regeneração tecidual (MARINHO, 2011).

\section{OBTENÇÃO DO PRP}

Para a obtenção do PRP é preciso seguir algumas etapas fundamentais para a preparação do gel, a fim de ter êxito na aplicação. Primeiramente o sangue é retirado por punção venosa, com cuidado no local para o sucesso do procedimento e conforto do paciente. Segundo Anitua (1999), o volume do sangue extraído no consultório odontológico varia de 10 a $20 \mathrm{ml}$ ou 70 a $120 \mathrm{ml}$. Deve-se priorizar sempre as veias dos membros superiores, evitando as veias dos membros inferiores, afim de minimizar riscos. $O$ material coletado fica próximo ao paciente, sendo preparado dessa forma: o sangue passa por uma centrífuga para que ocorra a separação das células, a máquina por sua vez irá separar o sangue da parte mais densa para a menos densa (FERREIRA, 2017).

O autor citado afirma que a primeira camada por sua vez será a formação do plasma pobre em plaquetas (PPP), a camada no centro será o plasma rico em plaquetas (PRP) e por fim estarão os eritrócitos.

Dando continuidade ao pensamento do autor supracitado, o PRP é levado para a sua segunda centrifugação que terá o objetivo de separar o plasma rico em plaquetas dos eritrócitos. Logo, após a segunda etapa do procedimento, o plasma rico em plaquetas já poderá ser utilizado em diversos procedimentos da Odontologia.

\section{RESULTADO E DISCUSSÃO}

Quadro 1: Artigos levantados nas bases de dados Biblioteca Virtual de Saúde, PubMed e Google Acadêmico.

\begin{tabular}{|c|c|c|c|c|}
\hline Procedência & Título do artigo & Autores & $\begin{array}{c}\text { Periódico (vol, } \mathbf{n}^{\circ}, \\
\text { pag, ano) }\end{array}$ & Considerações/Temática \\
\hline $\begin{array}{l}\text { Google } \\
\text { Acadêmico }\end{array}$ & $\begin{array}{l}\text { Avaliação do } \\
\text { sucesso de } \\
\text { implantes } \\
\text { osseointegráveis em } \\
\text { enxerto de seio } \\
\text { maxilar }\end{array}$ & $\begin{array}{l}\text { GONÇALV } \\
\text { ES, A. R. } \\
\text { Q. et al }\end{array}$ & $\begin{array}{l}\text { RGO. v. } 56 \text {, n. } 4 \text {, } \\
\text { p.423-427, } \\
\text { out./dez. } 2008\end{array}$ & $\begin{array}{l}\text { Descreve e avalia a } \\
\text { neoformação óssea (após a } \\
\text { implantação de implantes com } \\
\text { enxerto no seio maxilar } \\
\text { utilizando osso alógeno e o } \\
\text { plasma rico em plaquetas }\end{array}$ \\
\hline PubMed & $\begin{array}{l}\text { Effect of platelet-rich } \\
\text { plasma in the } \\
\text { treatment of } \\
\text { periodontal intrabony } \\
\text { defects in humans }\end{array}$ & $\begin{array}{l}\text { OUYANG } \\
\text { X. Y.; QIAO } \\
\text { J. }\end{array}$ & $\begin{array}{l}\text { Chinese Medical } \\
\text { Journal Chin Med } \\
\text { J. v.119, n.18, } \\
\text { p.1511-21, 2006. }\end{array}$ & $\begin{array}{l}\text { Realiza uma revisão integrativa } \\
\text { da literatura, avaliando a } \\
\text { eficácia do plasma rico em } \\
\text { plaquetas juntamente com osso } \\
\text { alógeno bovino em defeitos } \\
\text { intrabônicos humanos }\end{array}$ \\
\hline
\end{tabular}




\begin{tabular}{|c|c|c|c|c|}
\hline $\begin{array}{l}\text { Google } \\
\text { Acadêmico }\end{array}$ & $\begin{array}{l}\text { Plasma rico en } \\
\text { factores de } \\
\text { crecimiento en } \\
\text { cirugía bucal: } \\
\text { Presentación de } \\
\text { caso clínico. }\end{array}$ & $\begin{array}{l}\text { LÓPEZ, R. } \\
\text { G. F.; } \\
\text { BUENDÍA, } \\
\text { M. C. L.; } \\
\text { GONZÁLE } \\
\text { Z, E. R. }\end{array}$ & $\begin{array}{l}\text { Revista } \\
\text { Odontológica } \\
\text { Mexicana. v. 9, n. } \\
3, \text { p.141-146, set. } \\
2005 \text {. }\end{array}$ & $\begin{array}{l}\text { Descreve o uso do PRP junto } \\
\text { com um material de enxerto, em } \\
\text { caso clínico de um cisto } \\
\text { dentígero (odontoma), no local } \\
\text { do defeito ósseo após a } \\
\text { remoção da lesão. Observa os } \\
\text { resultados do tempo da } \\
\text { cicatrização }\end{array}$ \\
\hline PubMed & $\begin{array}{l}\text { Application of } \\
\text { platelet-rich plasma } \\
\text { for enhanced bone } \\
\text { regeneration in } \\
\text { grafted sinus. }\end{array}$ & $\begin{array}{l}\text { POESCHL, } \\
\text { P. W. et al. }\end{array}$ & $\begin{array}{l}\text { J Oral Maxillofac } \\
\text { Surg. v.70, n.3, } \\
\text { p.657-64, 2012. }\end{array}$ & $\begin{array}{l}\text { Apresenta um estudo clínico } \\
\text { realizado com } 14 \text { pacientes com } \\
\text { maxila atrofiada que foram } \\
\text { submetidos a cirurgia de enxerto } \\
\text { para o seio maxilar, utilizando o } \\
\text { plasma rico em plaquetas, } \\
\text { trombina, osso autógeno, } \\
\text { hidroxiapatita. Os resultados } \\
\text { obtidos foram descritos e } \\
\text { comparados com um grupo- } \\
\text { controle que não utilizou no } \\
\text { enxerto ósseo o plasma rico em } \\
\text { plaquetas }\end{array}$ \\
\hline PubMed & $\begin{array}{l}\text { Bone grafting the } \\
\text { jaws in the } 21 \mathrm{st} \\
\text { century: the use of } \\
\text { platelet-rich plasma } \\
\text { and bone } \\
\text { morphogenetic } \\
\text { protein }\end{array}$ & $\begin{array}{l}\text { CARLSON, } \\
\text { E. R }\end{array}$ & $\begin{array}{l}\text { Alpha Omegan. } \\
\text { v.93, n.3, p.26-30. } \\
2000 .\end{array}$ & $\begin{array}{l}\text { Avalia os benefícios do uso do } \\
\text { PRP em conjunto com o osso } \\
\text { autógeno }\end{array}$ \\
\hline $\begin{array}{l}\text { Google } \\
\text { Acadêmico }\end{array}$ & $\begin{array}{l}\text { Análise comparativa } \\
\text { do índice de } \\
\text { implantes } \\
\text { osteointegrados com } \\
\text { e sem a utilização de } \\
\text { PRP, no protocolo de } \\
\text { fixação. }\end{array}$ & $\begin{array}{l}\text { FERES } \\
\text { JUNIOR, F. } \\
\text { et al. }\end{array}$ & $\begin{array}{l}\text { Semina. v.25, p.9- } \\
22,2004 .\end{array}$ & $\begin{array}{l}\text { Analisa em um estudo de caso- } \\
\text { controle com implantes } \\
\text { instalados de marcas diferentes, } \\
\text { com e sem a utilização do PRP, } \\
\text { buscando avaliar os reais } \\
\text { benefícios da utilização do } \\
\text { plasma rico em plaquetas. }\end{array}$ \\
\hline $\begin{array}{l}\text { Biblioteca } \\
\text { Virtual de } \\
\text { Saúde }\end{array}$ & $\begin{array}{l}\text { Análise da reparação } \\
\text { óssea de alvéolos } \\
\text { após o } \\
\text { preenchimento com } \\
\text { plasma rico e pobre } \\
\text { em plaquetas }\end{array}$ & $\begin{array}{l}\text { ROMEIRO, } \\
\text { R. L.; } \\
\text { OLIVEIRA, } \\
\text { S. H. F.; } \\
\text { LORENZO, } \\
\text { J. L. }\end{array}$ & $\begin{array}{l}\text { Rev Assoc Paul Cir } \\
\text { Dent. v.62, n.4, } \\
\text { p.286-92, } 2008 .\end{array}$ & $\begin{array}{l}\text { Observou pela analise } \\
\text { histológica a reparação óssea } \\
\text { em alvéolos dentários após } \\
\text { exodontia, utilizando para o } \\
\text { preenchimento: plasma rico em } \\
\text { plaquetas ou rico em fribinas ou } \\
\text { o próprio colágeno. }\end{array}$ \\
\hline PubMed & $\begin{array}{l}\text { Osteogenesis } \\
\text { distraction and } \\
\text { platelet-rich plasma } \\
\text { for bone restoration } \\
\text { of the severely } \\
\text { atrophic mandibule: } \\
\text { preliminary results } \\
\end{array}$ & $\begin{array}{l}\text { ROBIONY, } \\
\text { M. et al. }\end{array}$ & $\begin{array}{l}\text { J Oral Maxillofac } \\
\text { Surg. v.60, n.6, } \\
\text { p.630-5, 2002. }\end{array}$ & $\begin{array}{l}\text { Avalia a utilização de plasma } \\
\text { rico em plaquetas associado a } \\
\text { osso autógeno em mandíbulas } \\
\text { endêntulas, a fim de observar a } \\
\text { eficácia dos biomateriais na } \\
\text { regeneração óssea. }\end{array}$ \\
\hline PubMed & $\begin{array}{l}\text { Using platelet-rich } \\
\text { plasma to accelerate } \\
\text { soft tissue maturation } \\
\text { in esthetic } \\
\text { periodontal surgery }\end{array}$ & $\begin{array}{l}\text { PETRUNG } \\
\text { ARO, P. S. }\end{array}$ & $\begin{array}{l}\text { Compend Contin } \\
\text { Educ Dent. v.22, } \\
\text { n.9, p.729-46. sep. } \\
2001 .\end{array}$ & $\begin{array}{l}\text { Demonstra através de } \\
\text { procedimentos cirúrgicos, a } \\
\text { utilização do PRP com tecidos } \\
\text { conjuntivos em casos de } \\
\text { recessão gengival em áreas } \\
\text { estéticas, analisando a } \\
\text { regeneração no local. }\end{array}$ \\
\hline
\end{tabular}




\begin{tabular}{|c|c|c|c|c|}
\hline PubMed & $\begin{array}{l}\text { Platelet gel in oral } \\
\text { and maxillofacial } \\
\text { surgery: a single- } \\
\text { centre experience }\end{array}$ & $\begin{array}{l}\text { DOMINIJA } \\
\text { NNI, A. et } \\
\text { al. }\end{array}$ & $\begin{array}{l}\text { Blood Transfus } \\
\text { v.10, p.200-4, } \\
\text { 2012. DOI } \\
\text { 10.2450/2012.0059 } \\
-11 .\end{array}$ & $\begin{array}{l}\text { Observou que o gel de } \\
\text { plaquetas é muito importante na } \\
\text { perda óssea alveolar, pois } \\
\text { apresenta propriedades } \\
\text { antissépticas, adesivas e } \\
\text { osteorregenerativas. Além de } \\
\text { ser bem tolerado e não ter } \\
\text { contraindicação, promove } \\
\text { aceleração de cicatrização nos } \\
\text { tecidos moles e regeneração } \\
\text { óssea mais rápida. }\end{array}$ \\
\hline PubMed & $\begin{array}{l}\text { Can autologous } \\
\text { platelet-rich plasma } \\
\text { gel enhance healing } \\
\text { after surgical } \\
\text { extraction of } \\
\text { mandibular third } \\
\text { molars? }\end{array}$ & $\begin{array}{l}\text { OGUNDIP } \\
\text { E OK, U. } \\
\text { Vl; } \\
\text { OWOTADE } \\
\text {, F. J. }\end{array}$ & $\begin{array}{l}\text { J Oral Maxillofac } \\
\text { Surg. v.69, n.9, } \\
\text { p.2305-10, } 2011 .\end{array}$ & $\begin{array}{l}\text { Demonstra através da análise } \\
\text { de dois grupos, que o grupo que } \\
\text { utilizou o PRP em alvéolos } \\
\text { dentários após exodontia de } \\
\text { terceiros molares inferiores } \\
\text { obteve uma redução da dor, } \\
\text { trismo e edema, além de ter } \\
\text { uma reparação óssea mais } \\
\text { rápida em comparação ao grupo } \\
\text { que não utilizou. }\end{array}$ \\
\hline PubMed & $\begin{array}{l}\text { Comparative } \\
\text { radiographic } \\
\text { evaluation of alveolar } \\
\text { bone healing } \\
\text { associated with } \\
\text { autologous } \\
\text { plateletrich plasma } \\
\text { after impacted } \\
\text { mandibular third } \\
\text { molar surgery }\end{array}$ & $\begin{array}{l}\text { CÉLIO- } \\
\text { MARIANO, } \\
\text { R.; MELO } \\
\text { W. M.; } \\
\text { CARNEIRO } \\
\text {-AVELINO, } \\
\text { C. }\end{array}$ & $\begin{array}{l}\text { J Oral Maxillofac } \\
\text { Surg. v.70, n.1, } \\
\text { p.19-24, } 2012 .\end{array}$ & $\begin{array}{l}\text { Ratifica que após análise de } 30 \\
\text { pessoas em dois grupos, os que } \\
\text { utilizaram o PRP no } \\
\text { preenchimento dos alvéolos } \\
\text { dentários após exodontias dos } \\
\text { terceiros molares, e os que não } \\
\text { utilizaram. Com a avaliação } \\
\text { radiográfica periapical de } 7 \text { dias, } \\
1,2,3 \text { e } 6 \text { meses com intuito de } \\
\text { avaliar a atuação do PRP. } \\
\text { Houve uma formação óssea } \\
\text { significativa nos três primeiros } \\
\text { meses. Sem diferenças no sexto } \\
\text { e sétimo mês. }\end{array}$ \\
\hline $\begin{array}{l}\text { Biblioteca } \\
\text { Virtual em } \\
\text { Saúde }\end{array}$ & $\begin{array}{l}\text { Utilização do plasma } \\
\text { rico em plaquetas na } \\
\text { odontologia }\end{array}$ & $\begin{array}{l}\text { CAMARGO } \\
\text {, G. A. C. et } \\
\text { al. }\end{array}$ & $\begin{array}{l}\text { Odontol. Clín.- } \\
\text { Cient., Recife, v.11, } \\
\text { n.3, p.187-190, } \\
\text { jul./set., } 2012 .\end{array}$ & $\begin{array}{l}\text { O uso do plasma rico em } \\
\text { plaquetas na Odontologia tem } \\
\text { trazido efeitos favoráveis tal } \\
\text { como, minimizar sangramento, e } \\
\text { até mesmo, acelerar } \\
\text { cicatrização com uma melhor } \\
\text { regeneração do tecido. Logo, há } \\
\text { necessidade de aprofundar-se } \\
\text { no assunto para confirmar a } \\
\text { eficiência do PRP a longo prazo. }\end{array}$ \\
\hline
\end{tabular}

\section{CONSIDERAÇÕES FINAIS}

Vê-se, portanto os inúmeros benefícios do plasma rico em plaquetas, por se tratar de um produto autólogo, atóxico, de fácil obtenção. Diversas pesquisas vêm comprovando sua utilização como adjuvante no processo de regeneração tecidual periodontal. A técnica selecionada para sua aplicação deverá obedecer à análise criteriosa das sequelas oriundas das patologias periodontais e, apenas após o controle da infecção ponderar se a aplicação é segura. Sendo assim, cabe aos profissionais o estudo do PRP, de suas técnicas e quais as suas indicações para cada caso, a fim de traçar o melhor plano de tratamento para cada paciente. 


\section{REFERÊNCIAS}

ANITUA, E. Plasma rich in growth factors: preliminary results of use in the preparation of future sites for implants. Int J. Oral Maxillofac Implants, v.14, p.529-35, 1999.

AZEVEDO, M. C. M. P. S. Aplicação do prf em medicina dentária. Monografia de investigação ou relatório de atividade clínica. Porto. 2014.

CAMARGO, G. A. C. et al. Utilização do plasma rico em plaquetas na odontologia. Odontol. Clín.-Cient., Recife, v.11, n.3, p.187-190, jul./set., 2012.

CARRANZA, F. A. Periodontia Clínica de Glickman. 5.ed. Rio de Janeiro: Interamericana, 1983, 968p.

CARLSON, E. R. Bone grafting the jaws in the 21 st century: the use of platelet-rich plasma and bone morphogenetic protein. Alpha Omegan. 2000, v.93, n.3, p.26-30.

CÉLIO-MARIANO, R.; MELO W. M.; CARNEIRO-AVELINO, C. Comparative radiographic evaluation of alveolar bone healing associated with autologous plateletrich plasma after impacted mandibular third molar surgery. J Oral Maxillofac Surg. v.70, n.1, p.19-24, 2012.

CORRÊA, M. G. Engenharia tecidual e regeneração periodontal. 2006. 46 f. Monografia (Especialização) Curso de Periodontia, Faculdade de Odontologia de Piracicaba, Universidade Estadual de Campinas, Piracicaba, 2006.

COSTA, P. A. SANTOS, P. Plasma rico em plaquetas: uma revisão sobre seu uso terapêutico. RBAC. v.48, n.4, p.311-9, 2016.

DINATO, C. J. et al. Plasma Rico em Plaquetas. In: DINATO, C. J.; POLIDO, D. W. Implantes osseointegrados: cirurgia e prótese. São Paulo: Artes Médicas, 2001. p. 315-342.

DOMINGUES, J. L. et al. A doença periodontal como possível fator de risco colaborador, dentre os demais fatores de risco clássicos, para o parto prematuro e/ou baixo peso ao nascer - revisão de literatura. R. Periodontia- v.20, n.2, p.33-38. jun., 2010.

DOMINIJANNI, A. et al. Platelet gel in oral and maxillofacial surgery: a single-centre experience. Blood Transfus v.10, p.200-4, 2012. DOI 10.2450/2012.0059-11.

FERES JUNIOR, F. et al. Análise comparativa do índice de implantes osteointegrados com e sem a utilização de PRP, no protocolo de fixação. Semina. v.25, p.9-22, 2004.

FERREIRA, R. M. Uso dos fatores de crescimento na odontologia. Dissertação apresentada a Universidade do Grande Rio. 2017.

GONÇALVES, A. R. Q. et al. Avaliação do sucesso de implantes osseointegráveis em enxerto de seio maxilar. RGO, Porto Alegre, v. 56, n. 4, p.423-427, out./dez. 2008

GONZÁLEZ, L. J. Plasma rico en plaquetas. Rev Esp Cirug Oral y Maxilofac., v.28, n.2, p.89-99, 2000.

LINDHE, J.; LANG N. P.; KARRING T. Tratado de Periodontia Clínica e Implantologia Oral. 5.ed. Rio de Janeiro: Guanabara Koogan, 2010, 1304p.

LÓPEZ, R. G. F.; BUENDÍA, M. C. L.; GONZÁLEZ, E. R. Plasma rico en factores de crecimiento en cirugía bucal: Presentación de caso clínico. Revista Odontológica Mexicana, Mexico, v. 9, n. 3, p.141-146, set. 2005.

MARINHO, C. M. Efeito do Plasma Rico em Plaquetas na regeneração periodontal. Revisão de literatura. Trabalho de Conclusão de Curso - Araçatuba: UNESP - Univ. Estadual Paulista; 2011. 
MENDES, Karina dal Sasso; SILVEIRA, Renata Cristina de Campos Pereira; GALVÃO, Cristina Maria. Revisão integrativa: método de pesquisa para a incorporação de evidências na saúde e na enfermagem. Texto Contexto Enferm, Florianópolis, v. 17, n. 4, p.758-764, 2008.

MELO, Márcia Borges de; BARBOSA, Maria Alves; SOUZA, Paula Regina de. Satisfação no trabalho da equipe de enfermagem: revisão integrativa. Rev. Latino-am. Enfermagem, Goiânia, v. 19, n. 4, p.1-9, 2011.

MORAES, G. F. REGENERAÇÃo TECIDUAL GUIADA. 2002. 53 f. Monografia bbb(Especialização) - Curso de Odontologia - Periodontia, Florianópolis, 2002.

$\mathrm{NANCl}, \mathrm{A}$. Ten Cate Histologia Oral: Desenvolvimento, estrutura e função. 7. ed. Rio de Janeiro: Elsevier Editora Ltda., 2008.

OGUNDIPE OK, U. VI; OWOTADE, F. J. Can autologous platelet-rich plasma gel enhance healing after surgical extraction of mandibular third molars?. J Oral Maxillofac Surg. v.69, n.9, p.2305-10, 2011.

OUYANG X. Y.; QIAO J. Effect of platelet-rich plasma in the treatment of periodontal intrabony defects in humans. Chinese Medical Journal Chin Med J. v.119, n.18, p.1511-21, 2006.

PEREIRA, S. G. Regeneração Periodontal: Proteínas de matriz do esmalte vs regeneração tecidual guiada. 2011. 68 f., Faculdade de Ciências da Saúde, Universidade Fernando Pessoa, Porto, 2011.

PEREIRA, S. G.; PINHO, M. M.; ALMEIDA, R. F. Regeneração periodontal em defeitos ósseos: Revisão de Literatura. Revista Portuguesa de Estomatologia, Medicina Dentária e Cirurgia Maxilofacial, Porto, v. 53, n. 1, p.53-59, 2012.

PETRUNGARO, P. S. Using platelet-rich plasma to accelerate soft tissue maturation in esthetic periodontal surgery. Compend Contin Educ Dent. v.22, n.9, p.729-46. sep. 2001.

POESCHL, P. W. et al. Application of platelet-rich plasma for enhanced bone regeneration in grafted sinus. J Oral Maxillofac Surg. V.70, n.3, p.657-64, 2012.

REQUICHA, J. F.; GOMES, M.; VIEGAS, C. Regeneração periodontal: presente e futuro. Revista Lusófona de Ciência e Medicina Veterinária. v.7, p.20-21, 2015.

REYES, L. M. et al. Utilización de plasma rico en plaquetas para regeneración periodontal en un perro. Revista Odontológica Mexicana Rev Odontol Mexicana. V.8, n.3, p.64-9, 2004.

ROBIONY, M. et al. Osteogenesis distraction and platelet-rich plasma for bone restoration of the severely atrophic mandibule: preliminary results. J Oral Maxillofac Surg. v.60, n.6, p.630-5, 2002.

ROSSI JUNIOR, R. et al. Utilização de plasma rico em plaquetas em enxertos ósseos para reparação de defeitos ósseos. Revista de Odontologia da Universidade Cidade de São Paulo, São Paulo, v. 20, n. 3, p.295-300, set./dez. 2008.

ROMEIRO, R. L.; OLIVEIRA, S. H. F.; LORENZO, J. L. Análise da reparação óssea de alvéolos após o preenchimento com plasma rico e pobre em plaquetas. Rev Assoc Paul Cir Dent. v.62, n.4, p.286-92, 2008.

SCARANTO, M. K. Plasma Rico em Plaquetas. 2002. 24p. Monografia (Especialização em Periodontia, Universidade Federal de Santa Catarina, Florianópolis.

SCARSO, J. et al. Plasma Rico em Plaquetas. In: DINATO, J. C.; POLIDO, W.D. Implantes Osseointegrados. 1. Ed. São Paulo: Artes Médicas, 2001. p.315-342.

WHITTEMORE, Robin; KNAFL, Kathleen. The integrative review: updated methodology. Journal Of Advanced Nursing, [s.I.], v. 52, n. 5, p.546-553, dez. 2005. 